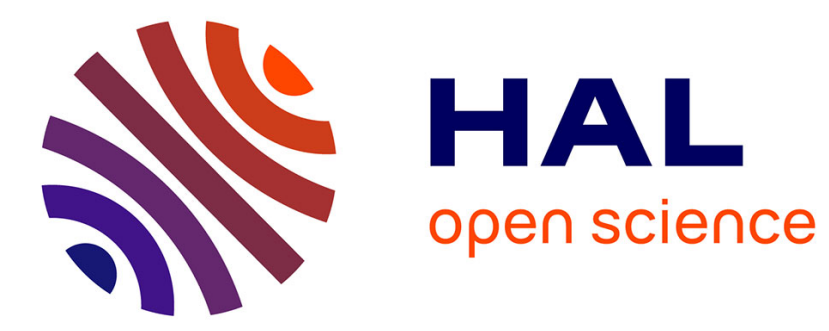

\title{
Single crystal diamond detector for radiotherapy
}

F Schirru, K Kisielewicz, T Nowak, B Marczewska

\section{To cite this version:}

F Schirru, K Kisielewicz, T Nowak, B Marczewska. Single crystal diamond detector for radiotherapy. Journal of Physics D: Applied Physics, 2010, 43 (26), pp.265101. 10.1088/0022-3727/43/26/265101. hal-00597822

\section{HAL Id: hal-00597822 \\ https://hal.science/hal-00597822}

Submitted on 2 Jun 2011

HAL is a multi-disciplinary open access archive for the deposit and dissemination of scientific research documents, whether they are published or not. The documents may come from teaching and research institutions in France or abroad, or from public or private research centers.
L'archive ouverte pluridisciplinaire HAL, est destinée au dépôt et à la diffusion de documents scientifiques de niveau recherche, publiés ou non, émanant des établissements d'enseignement et de recherche français ou étrangers, des laboratoires publics ou privés. 
Single Crystal Diamond Detector for Radiotherapy

\author{
F. Schirru ${ }^{* 1}$, K. Kisielewicz ${ }^{2}$, T. Nowak ${ }^{1}$, B. Marczewska ${ }^{1}$ \\ ${ }^{1)}$ Institute of Nuclear Physics Polish Academy of Science (IFJ), Kraków, Poland \\ ${ }^{2)}$ Centre of Oncology Maria Sktodowska - Curie Memorial Institute Kraków Branch (COOK), 31-115 Kraków, \\ ul.Garncarska 11, Poland
}

\begin{abstract}
The new generation of synthetic diamonds grown as CVD single crystal on HPHT substrate offers a wide range of applications. In particular, because of the near tissue equivalence and its small size (good spatial resolution), CVD single crystal diamond finds applicability in radiotherapy as dosemeter of ionizing radiation. In the present paper we report the electrical and dosimetric properties of a new diamond detector which was fabricated at IFJ and based on single crystal detector-grade CVD diamond provided of a novel contact metallization. Diamond properties were assessed at IFJ using a Theratron $680 \mathrm{E}$ therapeutic ${ }^{60} \mathrm{Co}$ gamma rays unit and at COOK with 6 and 18 MV X-rays Varian Clinac CL2300 C/D accelerator. The new dosemeter showed high electric and dosimetric performances: low value of dark current, high current at the level of some nA during irradiation, very fast dynamic response with a rise time amounting to parts of second, good stability and repeatability of the current and linearity of the detector signal at different dose and dose rate levels typically applied in radiotherapy. Results confirm the potential applicability of diamond material as dosemeter for applications in radiotherapy.
\end{abstract}

\title{
INTRODUCTION
}

The fast progress in medicine and all disciplines of human health protection requires the development of new methods of dose calculation, dose delivery and dose verification. At the modern radiotherapy facilities new non-conventional and highly conformal treatments such as stereotactic treatments and intensity-modulated radiation therapy (IMRT) are routinely applied and allow us to save organs at risk delivering the dose exactly to the tumor (target area). These treatments usually involve large dose gradients and fast dose rate changes which require the development of radiation dosemeters having small active dimension (i.e. high spatial resolution) and fast dynamic response in order to follow the dose rate variation in the radiation field.

Since years diamond has been considered as a perfect candidate to work as a detector of ionizing radiation for radiotherapy due to its unique properties such as tissue-equivalence, chemical resistance, high sensitivity to radiation and radiation hardness.

At present, diamond detectors based only on natural gems and produced by the PTW Freiburg company are commercially available on the market. Different publications [1-4] can be found in literature concerning the applicability of synthetic diamond as radiation dosemeter. So far however, due to the limitations mainly imposed by the quality of the samples [5-8], there is still the lack of a real product which could equip the hospital facilities.

A considerable progress in the diamond growth was achieved recently due to the adaptation of CVD (Chemical Vapour Deposition) method to the growth of high-quality single crystal diamond films [9-12]. In this process, HPHT (High Pressure High Temperature)

\footnotetext{
${ }^{1}$ Corresponding author: e-mail: F.Schirru@surrey.ac.uk, Phone: +44 0148368 2730, Fax: +44 01483686781
} 
single crystals with a special orientation are usually used as substrate or seed. After cutting off the substrate layer and polishing the crystal surface, the free standing single crystal can be available for the experiments. Synthetic diamonds offered now on the market have sufficiently good quality to compete with the natural gems which are strongly selected from thousands. The successful construction of a detector however does not depend only on the quality of the crystals but also on the electric contacts, holders and electronic which should be properly optimized.

At IFJ we developed a new diamond dosemeter which is based on the last generation of commercial detector-grade single crystal CVD diamond (SC CVD) provided of a novel ohmic contacts. The sample was, at first, preliminary investigated at IFJ under ${ }^{60} \mathrm{Co}$ gamma rays beam on regard to its electrical properties i.e. dark current, dynamic response, stability and repeatability of the current signal under irradiation. Next, it was encapsulated in a solid-water plastic holder of a "finger" shape and tested at COOK under 6 and $18 \mathrm{MV}$ X-rays beam as radiation dosemeter performing measurements on its sensitivity, linearity with the dose and dose rate at levels relevant for radiotherapy applications and dependence on the beam energy.

Aim of this paper is to show the potentiality of the new device for medical application in radiotherapy.

\section{MATERIAL AND METHODS}

The material considered within this work consists of one SC CVD diamond commercially obtained from the Diamond Detector Ltd. (DDL) company. The sample, labeled DD4, has dimensions of $4.7 \times 4.7 \mathrm{~mm}^{2}$ and is $500 \mu \mathrm{m}$ thick. It has detector-grade quality i.e. characterized by a very low amount of Nitrogen and Boron in the order of less than $5 \mathrm{ppb}$.

The diamond sample was ordered with a novel ohmic metallization in a sandwich configuration with a central dot of $3 \mathrm{~mm}$ of diameter which leads to an active volume of $v=3.5 \cdot 10^{-3} \mathrm{~cm}^{3}$. The new contacts were fabricated by sputtering deposition of a diamond-like carbon $(3 \mathrm{~nm})$ layer followed by a layer of platinum and gold respectively 16 and $200 \mathrm{~nm}$ thick [13].

To test the dosimetric properties, the sample had to be properly encapsulated into a holder. Construction of the new holder was made at IFJ using a standard grade Solid Water ${ }^{\circledR}$ GAMMEX 457 of density $\rho=1.05 \mathrm{~g} \cdot \mathrm{cm}^{-3}$ which does not affect the photon beam and presents nearly equivalent absorption characteristics of water over a wide range of energies relevant in clinical dosimetry. The holder has a cylindrical shape with diameter of $9 \mathrm{~mm}$ and $25 \mathrm{~mm}$ of length. To avoid the influence of the air on the detector signal, the holder cavity was properly tailored to the shape of the crystal.

Measurements of current were performed with a Keithley 6517A electrometer which served also as a voltmeter to apply the appropriate bias voltage between the electric contacts.

Irradiations were performed at IFJ using a Theratron $680 \mathrm{E}$ unit ${ }^{60} \mathrm{Co}$ gamma rays source with $1.25 \mathrm{MeV}$ photon mean energy and at COOK using an X-rays linear accelerator Varian Clinac CL2300 C/D at 6 and 18 MV. Dosimetric measurements were performed at $d_{\max }$ (depth of maximum dose) by using PMMA slabs of different thickness, area of $20 \times 20 \mathrm{~cm}^{2}$ and provided of drilled holes for the placement of the diamond detector itself.

Dose rate was estimated with a Markus $0.125 \mathrm{~cm}^{3}$ ionization chamber connected to a PTW universal dosemeter T10001 while a PTW natural diamond detector served as a reference dosemeter.

\section{RESULTS}

At first, we evaluated the electrical quality of the sample DD4 by measuring its dark current as a function of the applied bias in the range $\pm 500 \mathrm{~V}$. The results presented in Fig. 1 indicate the quasi-ohmic behavior of the contacts with a dark current value below $\pm 2 \mathrm{pA}$ for a 
maximum applied bias of $\pm 500 \mathrm{~V}$. Measurements were performed in darkness and data reported in Fig. 1 were calculated averaging on all recorded points after stabilization of the dark current (usually half an hour). The sample shows a resistivity of $3.9 \cdot 10^{15} \Omega \cdot \mathrm{cm}$ as deduced from the dark current measurement at $+500 \mathrm{~V}$.

Before evaluating other parameters, first of all we preliminary checked the current behavior of the sample under ${ }^{60} \mathrm{Co}$ gamma rays beam at different applied voltages. For biases $> \pm 100 \mathrm{~V}$ we observed a strong instability of the current signal while for biases below such threshold the signal was found to be very stable. Also a fast dynamic response was observed in particular for $-10 \mathrm{~V}$. Such behavior is not clear and requires a separate study which was not performed within this work.

Fig. 2 illustrates the two minutes current response of our sample under ${ }^{60} \mathrm{Co}$ irradiation at dose rate of $1 \mathrm{~Gy} / \mathrm{min}$ and $-10 \mathrm{~V}$ of applied voltage. As it is possible to observe, the diamond sample shows very fast response and does not present any priming or overshoot effect which usually are present in those diamonds of poor quality. Before irradiation, the recorded dark current was $I_{D C} \sim 2.5 \cdot 10^{-13}$ A. After switching on the ${ }^{60}$ Co source, the induced current reached within one second a stable value of $I_{R} \sim 1.27 \cdot 10^{-8} \mathrm{~A}$ leading to a high signal to noise ratio of $\mathrm{S} / \mathrm{N} \sim 5.1 \cdot 10^{4}$. When the irradiation was switched off, the current dropped, within few seconds, to the previous value of the dark current. Due to the high quality of the electric contacts, the current signal under irradiation was very stable and did not exceed the $0.5 \%$ of variation respect its average value. These results confirm that the novel ohmic metallization composed of thin layers of diamond-like carbon, platinum and gold shows better properties compared to other kind of electric contacts as previously reported [14].

The repeatability of the current signal was checked performing five irradiations at the same operating conditions. Each cycle reported in Fig. 3 was characterized by one minute of irradiation followed by another minute of break. Taking the integral of each pulsed irradiation and averaging the values of area we found a good coefficient of repeatability of $\sim 0.4 \%$.

The quality of a detector can be estimated by the knowledge of its gain factor $G$ or charge collection efficiency. Such parameter is defined as $G=I_{R} / I_{P}$ where $I_{R}$ is the recorded detector current and $I_{P}$ is the theoretical current induced by the irradiation field which is defined as:

$$
I_{P}=D \rho e v / w
$$

Assuming a dose rate $D=1 \mathrm{~Gy} / \mathrm{min}$, a sensitive volume of the sample of $v=3.5 \cdot 10^{-3} \mathrm{~cm}^{3}$, the density of diamond $\rho=3.5 \mathrm{~g} / \mathrm{cm}^{3}$, the electronic charge $e=1.6 \cdot 10^{-19} \mathrm{C}$ and $w=13 \mathrm{eV}$ as energy required to produced an electron-hole pair in diamond, we obtain $I_{P}=15.7 \mathrm{nA}$. Considering as previously reported $I_{R} \sim 1.27 \cdot 10^{-8} \mathrm{~A}$, we obtain a gain factor of $G=0.8$ which, being close to the unity, demonstrates the high quality of our SC CVD sample. To be noticed that the value of gain factor here calculated is higher than those reported in literature for commercially available natural diamonds which usually is quoted to 0.5 [15-17].

To have a better estimation of the time required to have complete stabilization of the current under irradiation, the electrometer was set to record the experimental data every $0.2 \mathrm{~s}$. As reported in Fig. 4, the induced current reached the stabilization within one recording point i.e. within $0.2 \mathrm{~s}$ after switching on the ${ }^{60} \mathrm{Co}$ source. Such measurement clearly demonstrates the fast response of the sample DD4 and its potential applicability as radiation dosemeter in radiotherapy.

As a further step, first we developed a new radiation dosemeter by encapsulation of the SC CVD diamond sample and then we investigated the dosimetric properties of the new device to assess its suitability for radiotherapy applications.

Dose dependence of the diamond device was investigated performing irradiations with the ${ }^{60} \mathrm{Co}$ gamma-rays photon beam which, with its constant output guarantees more stable 
exposure at very low delivered doses. The detector was biased at $-10 \mathrm{~V}$ and experimental data were collected in the dose range $0.1-4.0 \mathrm{~Gy}$ at the dose rate of $2.0 \mathrm{~Gy} / \mathrm{min}$. Performing a linear fit to the experimental data reported in Fig. 5 and normalizing to the sample volume we obtain a value of sensitivity of $(1.65180 \pm 0.00006) \cdot 10^{-7} \mathrm{C} \cdot \mathrm{Gy}^{-1} \cdot \mathrm{mm}^{-3}$. To be noticed that data reported on Fig. 5 show a linear dependence even at low values of absorbed dose as demonstrated by analysing the derivative of the net charge. As a matter of comparison, we next evaluated the dose dependence for a PTW natural diamond. The analysis performed on the experimental data led to a sensitivity per unit of volume of $(5.8540 \pm 0.0001) \cdot 10^{-8} \mathrm{C} \cdot \mathrm{Gy}^{-1} \cdot \mathrm{mm}^{-3}$ which is more than 2 times lower than that obtained for the new diamond dosemeter.

Dose rate dependence was evaluated using the ${ }^{60} \mathrm{Co}$ gamma-rays photon beam, 6 and $18 \mathrm{MV}$ X-rays beams as well. Measurements under ${ }^{60} \mathrm{Co}$ beam (Fig. 6) were performed in the dose rate range of $0.5-2.0 \mathrm{~Gy} / \mathrm{min}$ by changing the distance between the radiation source and the surface of the PMMA slab in which the diamond dosemeter was positioned. Measurements under 6 and $18 \mathrm{MV}$ X-rays beams (Fig. 7) were performed in the range of dose rate $1.0-6.0 \mathrm{~Gy} / \mathrm{min}$ by changing the pulse repetition frequency of the accelerator. In this case, the distance between the source and the PMMA slab $(100 \mathrm{~cm})$ had to be slightly adjusted when changing the beam energy from 6 to $18 \mathrm{MV}$. Fowler's model [18] predicts a dose rate $d D / d t$ dependence of the detector current $I$ as:

$$
I=c \cdot\left(\frac{d D}{d t}\right)^{\Delta}
$$

where $c$ is a constant and $\Delta$ an exponential parameter which describes the deviation from the linearity. According to this model, $\Delta$ is equal to 0.5 in the case of pure semiconductor with ohmic contacts and no traps. If all traps have the same capture cross section, then $\Delta$ falls between 0.5 and 1 reaching the upper limit for a uniform or quasi-uniform trap distribution. $\Delta$ may also exceed the unit if traps with different capture cross sections are present in the crystal [18]. Tab. 1 reports the values of the parameter $\Delta$ calculated by fitting the experimental data with Eq. (2) obtained for the new diamond device and the PTW natural diamond detector. The results indicate negligible dose rate dependence for both devices in the range of dose rate investigated.

The photon energy response of the two dosemeters was the other important dosimetric property investigated in this work. It was assessed by measuring the charge sensitivity of the detectors as a function of the mean photon energy of ${ }^{60} \mathrm{Co}$ gamma, $6 \mathrm{MV}$ and $18 \mathrm{MV} \mathrm{X}$-rays photom beams at dose rate of 1 and 2 Gy/min. As shown in Fig. 8, the response of the diamond device was found to be almost independent on the beam energy. The sensitivity exhibited a variation in the order of the $0.2 \%$ respect its mean value which could be related to the material encapsulation of which the dosemeter is manufactured [8]. Measurements on the PTW natural diamond reported a slight dependence on the beam energy with a variation of the sensitivity in the order of $1.5 \%$ respect its mean value.

\section{CONCLUSIONS}

A new radiation dosemeter based on high quality SC CVD diamond provided of a novel ohmic metallization has been fabricated and tested in order to assess its dosimetric properties (dose response, dose rate dependence and photon energy dependence under ${ }^{60} \mathrm{Co}$ gamma rays and X-rays beams). Measurements were performed applying dose and dose rate levels typical for radiotherapy and the results were compared with those obtained from a commercially available PTW natural diamond. Results here reported demonstrate the potential applicability 
of the new device as a radiotherapy dosemeter and its dosimetric properties can be summarized as follows:

- linearity respect the absorbed dose even at low values as a consequence of its fast response $(0.2 \mathrm{~s}$ to get the current signal stabilization under irradiation). Its sensitivity per unit of volume was found to be in the order of $\sim 1.65 \cdot 10^{-7} \mathrm{C} \cdot \mathrm{Gy}^{-1} \cdot \mathrm{mm}^{-3}$ more than 2 times higher than that obtained from the diamond detector PTW;

- linearity respect the dose rate applied, in the range $0.5-2.0 \mathrm{~Gy} / \mathrm{min}$ for gamma rays and in the range $1.0-6.0 \mathrm{~Gy} / \mathrm{min}$ for 6 and $18 \mathrm{MV} \mathrm{X}$-rays beams;

- negligible dependence on the beam energy related to the tissue-equivalence of the encapsulation and diamond itself.

The results not only evidence the high quality of single crystal synthetic diamonds which now can be achieved by CVD techniques but also the role of the novel contact metallization which contributed positively to the quality of the current signal in terms of stability and speed response. The combination of these two aspects opens new perspectives on application of synthetic diamonds as dosemeter for radiotherapy applications. However, the reported work regarded the dosimetric properties of one particular SC CVD diamond. As a further step therefore, it would be interesting to produce a certain number of diamond dosemeter based on a batch of several crystals obtained from the same source in order to check the statistical fluctuations of repeatability of their dosimetric properties.

\section{REFERENCES}

[1] A. Fidanzio, L. Azario, R. Kalish, Y. Avigal, G. Conte, P. Ascarelli, A. Piermattei, Med. Phys. 32, 389-395, (2005).

[2] C. De Angelis, M. Bucciolini, M. Casati, I. Lřvik, M. Bruzzi, S. Lagomarsino, S. Sciortino, S. Onori, Radiat. Protect. Dosim. 120, 38-42, (2006).

[3] S. Ramkumar, C. M. Buttar, J. Conway, A. J. Whitehead, R. S. Sussmann, G. Hill, S. Walker, Nucl. Instrum. Meth. A 460, 401-411, (2001).

[4] M. J. Guerrero, D. Tromson, C. Descamps, P. Bergonzo, Diam. Relat. Mat. 15, 811-814, (2006).

[5] G. A. P. Cirrone, G. Cuttone, S. Lo Nigro, V. Mongelli, L. Raffaele, M. G. Sabini, L. Valastro, M. Bucciolini, S. Onori, Nucl. Instr. and Meth. A 552, 197-202, (2005).

[6] M. J. Guerrero, D. Tromson, P. Bergonzo, R. Barrett, Nucl. Instr. and Meth. A 552, 105111, (2005).

[7] M. Bucciolini, E. Borchi, M. Bruzzi, M. Casati, P. Cirrone, G. Cuttone, C. De Angelis, I. Lřvik, S. Onori, L. Raffaele, S. Sciortino, Nucl. Instr. and Meth. A 552, 189-196, (2005).

[8] C. De Angelis, M. Casati, M. Bruzzi, S. Onori, M. Bucciolini, Nucl. Instr. and Meth. A 583, 195-203, (2007).

[9] N. Tranchant, D. Tromson, C. Descamps, A. Isambert, H. Hamrita, P. Bergonzo, M. Nesladek, Diam. Relat. Mat. 17, 1297-1301 (2008).

[10] C. Descamps, D. Tromson, N. Tranchant, A. Isambert, A. Bridier, C. De Angelis, S. Onori, M. Bucciolini, P. Bergonzo, Radiation Measurements 43, pp 933-938, (2008).

[11] S. Almaviva, Marco Marinelli, E. Milani, A. Tucciarone, G. Verona-Rinati, R. Consorti, A. Petrucci, F. De Notaristefani, I. Ciancaglioni, Nucl. Instr. and Meth. A 594, 273-277, (2008).

[12] S. P. Lansley, G.T. Betzel, F. Baluti, L. Reinisch, J. Meyer, Nucl. Instr. and Meth. A 607, 659-667, (2009).

[13] A. Galbiati, U.K. patent application number 0819001.9, October 2008. 
[14] A. Galbiati, S. Lynn, K. Oliver, F. Schirru, T. Nowak, B. Marczewska, J. A. Dueńas, R. Berjillos, I. Martel, L. Lavergne, IEEE TRANS. On NUCL. SC., 56, No. 4, 1863-1874, (2009).

[15] B. Planskoy, Phys. Med. Biol. 25, 519-532 (1980).

[16] P. W. Hoban, M. Heydarian, W. A. Beckam, A. H. Beddoe, Phys. Med. Biol. 39, 1219-1292, (1994).

[17] A. Piermattei, L. Azario, A. Fidanzio, G. Arcovito, Phys. Med. 14, 9-17, (1998).

[18] J. F. Fowler, in: F. H. Attix, W. C. Roesch (Eds.), Radiat. Dosim., Academic, New York, 2, 241-324, (1966).

Table 1

$\Delta$ parameters of the diamond dosemeters DD4 and PTW under ${ }^{60} \mathrm{Co} \gamma$-rays, $6 \mathrm{MV}$ and $18 \mathrm{MV}$ $\mathrm{X}$-rays photom beams calculated by fitting the experimental data with Eq. (2).

\begin{tabular}{|c|c|c|c|}
\hline Device & $\boldsymbol{\Delta}\left({ }^{\mathbf{6 0}} \mathbf{C o}\right)$ & $\boldsymbol{\Delta}(\mathbf{6} \mathbf{M V})$ & $\boldsymbol{\Delta}(\mathbf{1 8} \mathbf{M V})$ \\
\hline DD4 & $1.007 \pm 0.003$ & $1.020 \pm 0.008$ & $1.014 \pm 0.008$ \\
\hline PTW & $1.009 \pm 0.001$ & $0.998 \pm 0.009$ & $0.999 \pm 0.008$ \\
\hline
\end{tabular}

\section{FIGURES}

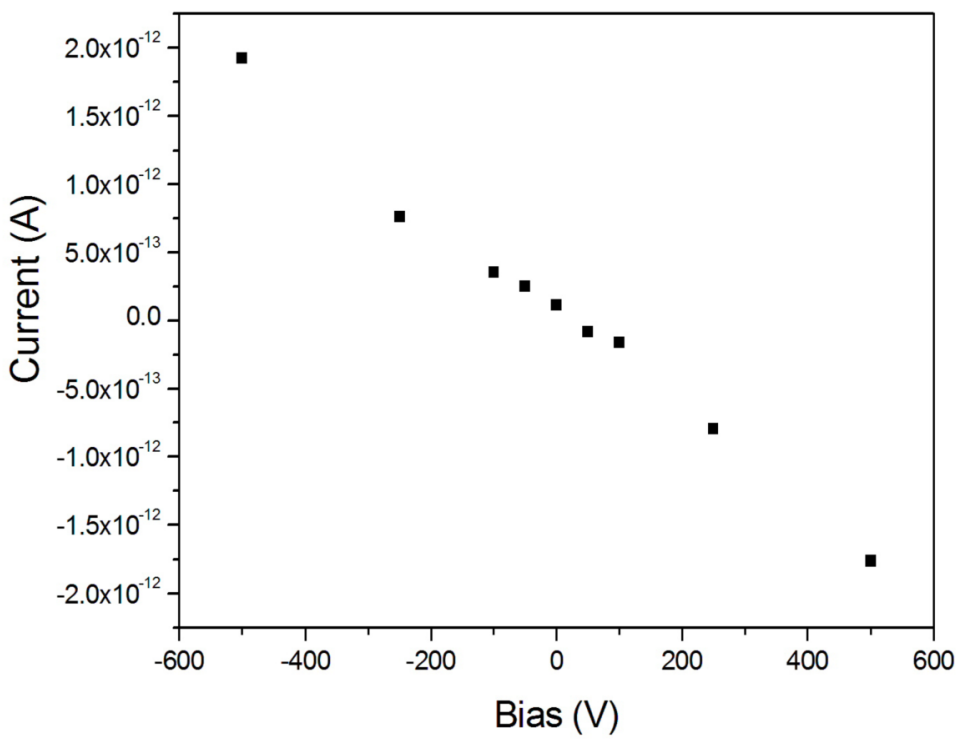

Fig. 1 Dark current of the diamond sample DD4. 


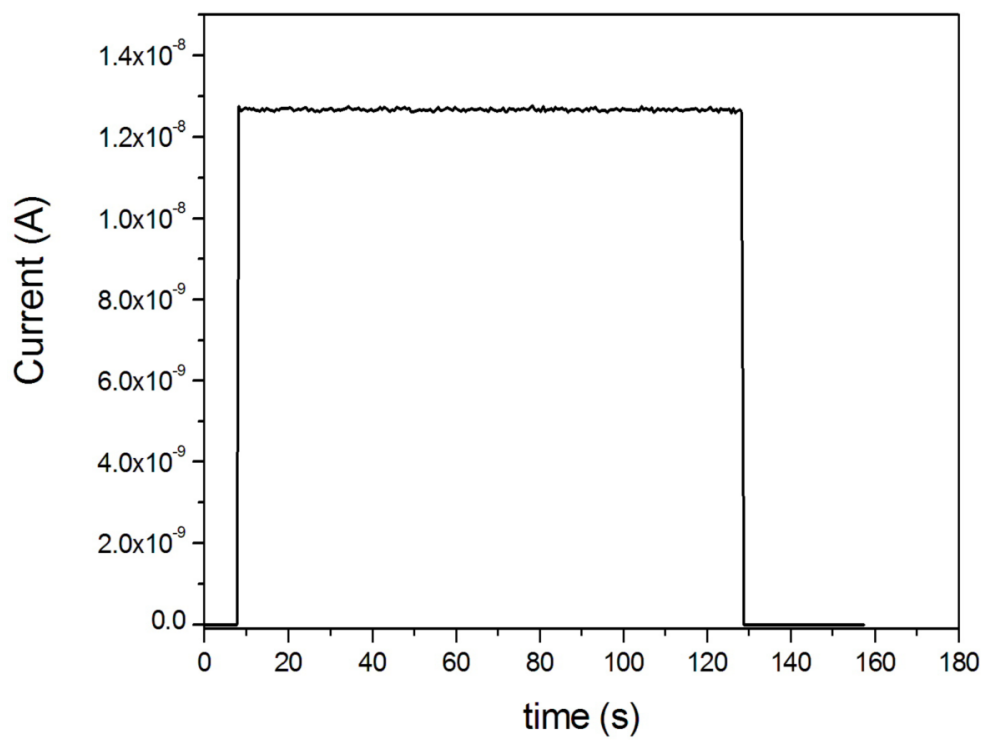

Fig. 2 Current response of the sample DD4 under ${ }^{60} \mathrm{Co}$ irradiation at dose rate of $1 \mathrm{~Gy} / \mathrm{min}$.

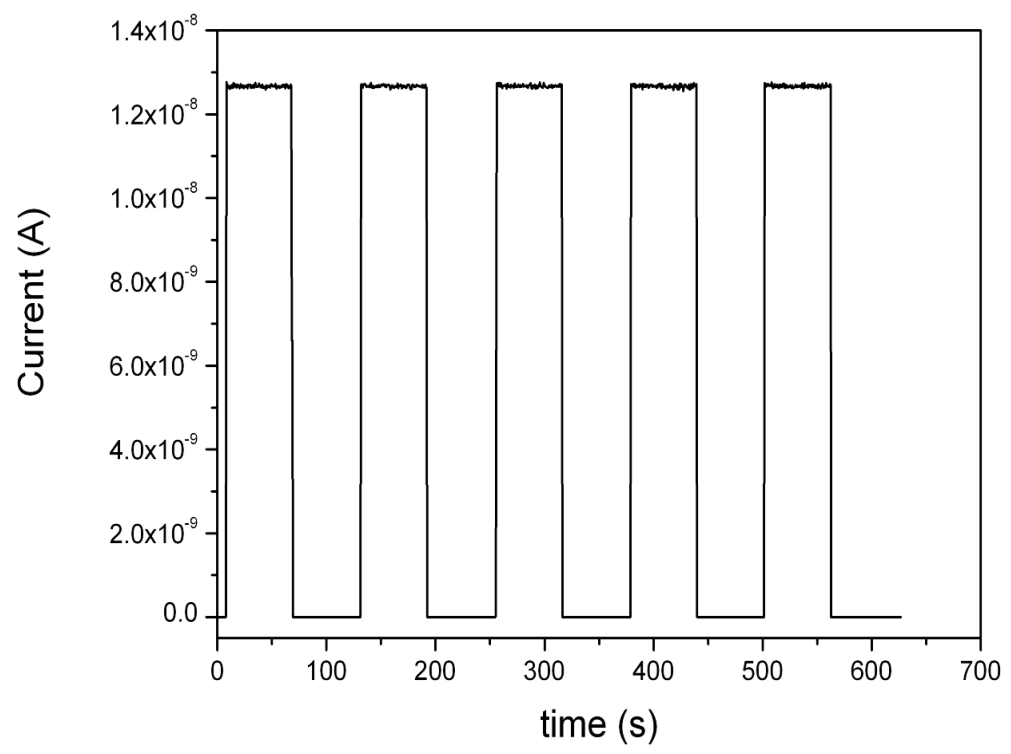

Fig. 3 Signal repeatability of the sample DD4 under ${ }^{60} \mathrm{Co}$ irradiation at dose rate of $1 \mathrm{~Gy} / \mathrm{min}$. 


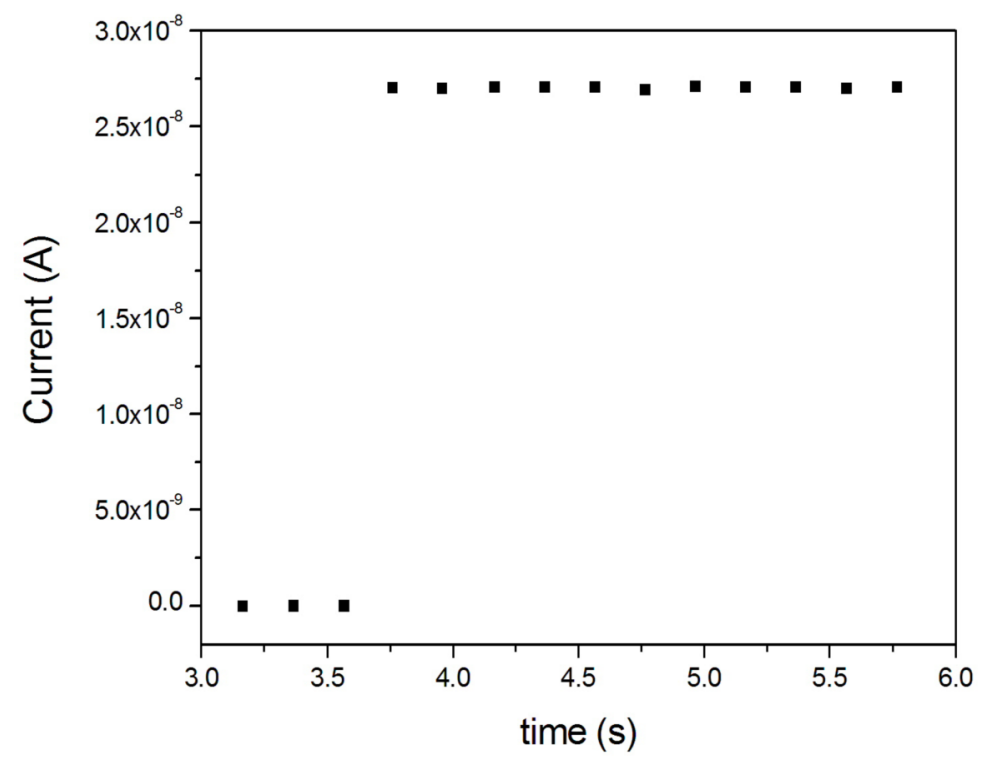

Fig. 4 Current response of the diamond sample DD4 under ${ }^{60} \mathrm{Co}$ irradiation at $1 \mathrm{~Gy} / \mathrm{min}$ and bias of $+100 \mathrm{~V}$. Data were recorded with a sampling time of $0.2 \mathrm{~s}$.

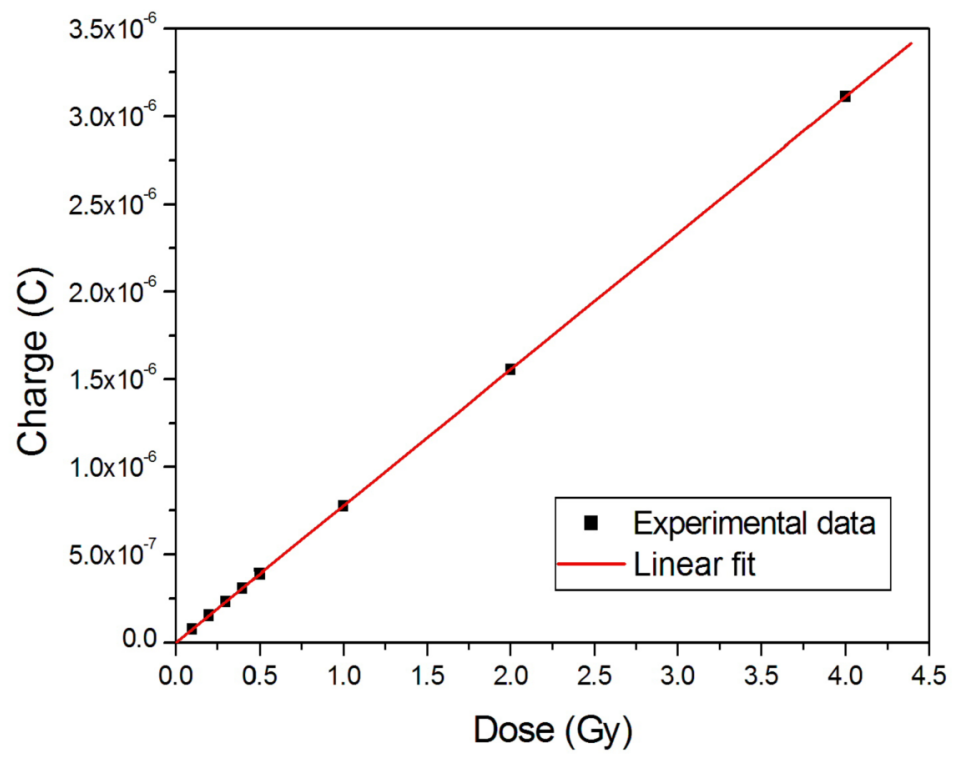

Fig. 5 Dose response of the diamond dosemeter in the range $0.1-4.0$ Gy under ${ }^{60} \mathrm{Co}$ gamma rays photon beam. 


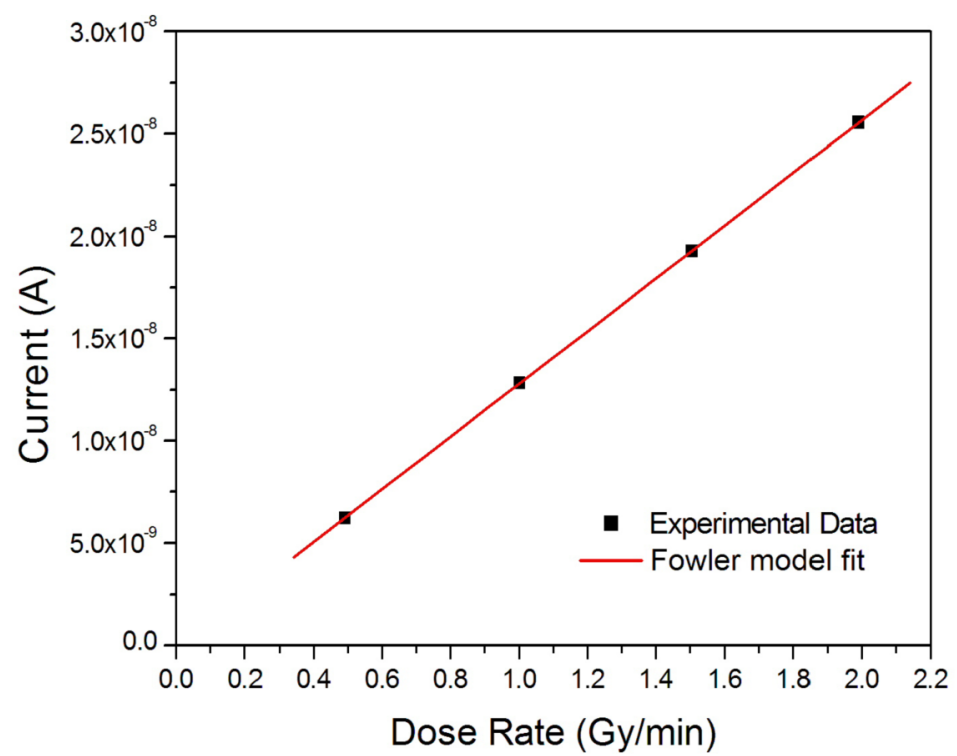

Fig. 6 Dose rate response of the diamond dosemeter in the range $0.5-2.0 \mathrm{~Gy} / \mathrm{min}$ under ${ }^{60} \mathrm{Co}$ gamma rays photon beam. The device was biased at $-10 \mathrm{~V}$.

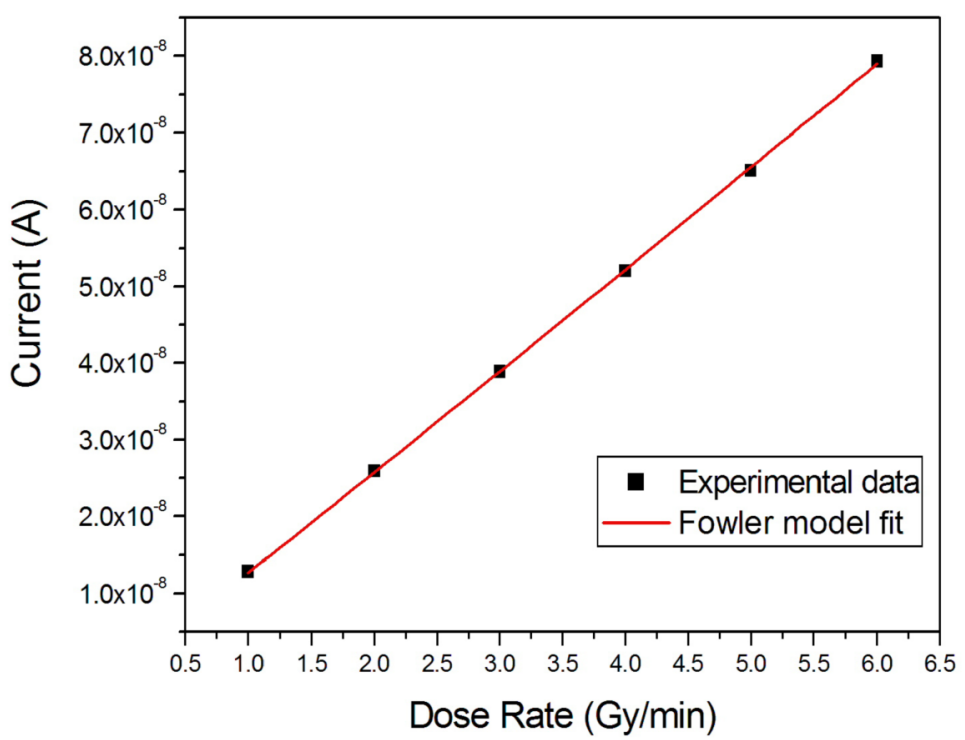

Fig. 7 Dose rate response of the diamond device in the range $1.0-6.0 \mathrm{~Gy} / \mathrm{min}$ under $6 \mathrm{MV}$ $\mathrm{X}$-rays photon beam. The device was biased at $-10 \mathrm{~V}$. 


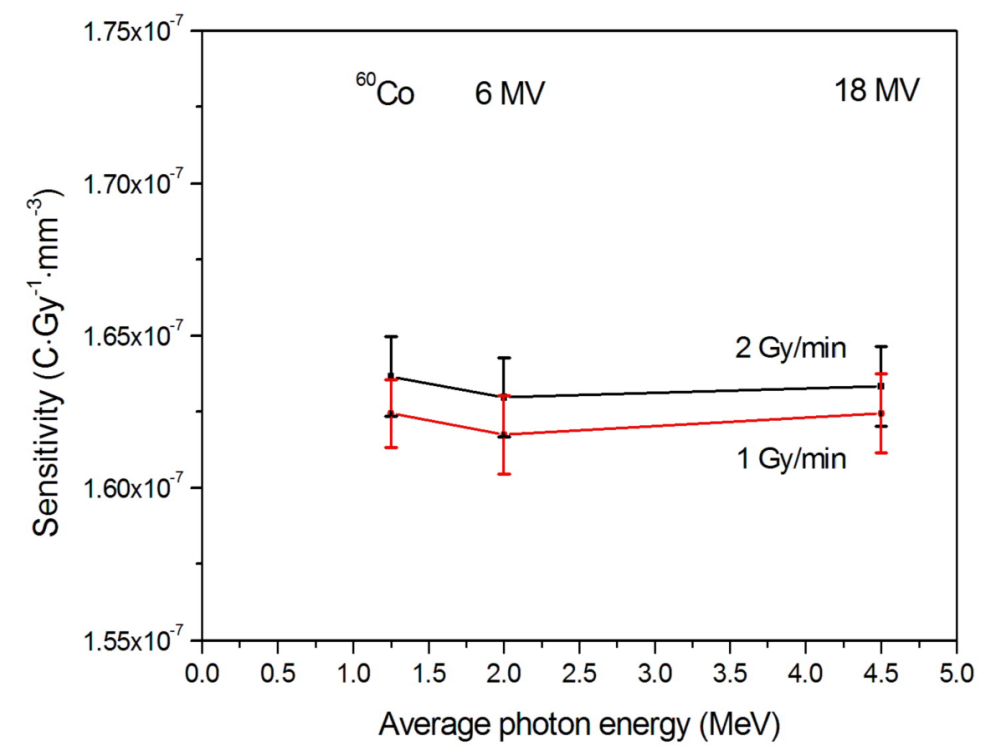

Fig. 8 Energy response of the diamond dosemeter evaluated for 1 and $2 \mathrm{~Gy} / \mathrm{min}$ under ${ }^{60} \mathrm{Co}$, 6 and $18 \mathrm{MV}$ photon beams. The device was biased at $-10 \mathrm{~V}$. Errors (one standard deviation) correspond to the uncertainty on the dose rate estimation at different radiation fields. 